\title{
IMPLEMENTASI FRAMEWORK ACCELERATED MOBILE PAGES PADA PENGEMBANGAN WEBSITE PROGRAM STUDI SISTEM INFORMASI
}

\author{
${ }^{[1]}$ Dicki Darmawan Saputra, ${ }^{[2]}$ Ilhamsyah, ${ }^{[3]}$ Dian Prawira \\ [1][2][3]Jurusan Sistem Informasi, Fakultas MIPA Universitas Tanjungpura \\ Jalan Prof. Dr. H. Hadari Nawawi, Pontianak \\ Telp./Fax. :(0561) 577963 \\ e-mail: ${ }^{[1]}$ dickidarmawansaputra@ student.untan.ac.id, ${ }^{[2]}$ ilhamsyah@ @isfo.untan.ac.id, \\ ${ }^{[3]}$ dianprawira@sisfo.untan.ac.id
}

\begin{abstract}
Abstrak
Kebutuhan akses informasi melalui internet setiap tahunnya terus meningkat, hal tersebut terlihat dari terus bertumbuhnya jumlah pengguna aktif internet dan smartphone. Berdasarkan data lembaga riset digital marketing Emarketer, memperkirakan pada tahun 2018 jumlah pengguna aktif smartphone di Indonesia lebih dari 100 juta orang. Dengan banyaknya pengguna aktif smartphone di Indonesia, memungkinkan akses mencari informasi melalui website menggunakan smartphone banyak dilakukan oleh masyarakat dan tidak terkecuali akses mencari informasi seputar Program Studi Sistem Informasi. Program Studi Sistem Informasi FMIPA UNTAN didirikan pada tanggal 19 Mei 2014 dan menjadi salah satu Program Studi yang cukup banyak diminati. Agar dapat mendukung pengguna aktif smartphone mengakses informasi melalui website, maka perlu diterapkan teknologi baru agar optimal dalam penggunaan di smartphone dan meningkatkan performa website saat diakses. Adapun pengoptimalan website Program Studi Sistem Informasi dengan menerapkan framework AMP (Accelerated Mobile Pages). AMP merupakan solusi untuk situs web seluler yang lebih cepat dan ringan yang bertujuan untuk menyediakan konten kepada pengguna lebih cepat saat pemuatan halaman web. Kemudian setelah implementasi AMP pada sistem dilakukan pengujian fungsional dengan diperoleh kesimpulan berhasil dan pengujian antarmuka diperoleh nilai 88,07\% dari 46 responden. Adapun untuk pengujian kode AMP dengan Google AMP Test dan AMP Validator diperoleh hasil valid dan lulus. Sedangkan pengujian performa pada sistem yang menggunakan cloud server dengan PageSpeed Insights untuk mode mobile diperoleh hasil total skor 1187 poin dan GTMetrix diperoleh total skor PageSpeed 1292\% dan total skor YSlow 1257\%.
\end{abstract}

Kata Kunci:Accelerated Mobile Pages, Google AMP, PageSpeed Insights, GTMetrix, AMP Testing Tools.

\section{PENDAhULUAN}

Berdasarkan Keputusan Menteri Nomor: 442/E.E2/DT/2014 tanggal 19 Mei 2014, Jurusan/Program Studi Sistem Informasi Fakultas Matematika dan Ilmu Pengetahuan Alam (FMIPA) Universitas Tanjungpura (UNTAN) sejak pendiriannya sudah berusaha menerapkan Kurikulum Berbasis Kompetensi (KBK) [1]. Adapun Program Studi Sistem Informasi mempunyai visi menjadi Program Studi yang diakui secara nasional dalam bidang penerapan Sistem Informasi yang berkualitas dan lulusannya mampu bersaing di pasar lokal, regional dan internasional pada tahun 2023.

Program Studi Sistem Informasi FMIPA
UNTAN berdiri pada tahun 2014 dan merupakan salah satu Program Studi yang cukup banyak diminati oleh masyarakat. Hal tersebut terlihat dari setiap tahunnya banyak calon mahasiswa/mahasiswi yang mengambil kuliah di Program Studi Sistem Informasi. Akan tetapi, kurangnya informasi seputar Program Studi Sistem Informasi membuat belum maksimalnya informasi yang diterima oleh masyarakat tentang Program Studi Sistem Informasi. Hal ini disebabkan oleh belum maksimalnya penggunaan media website Program Studi Sistem Informasi untuk menyampaikan informasi seputar Program Studi Sistem Informasi. 
Berdasarkan lembaga riset digital marketing Emarketer memperkirakan pada tahun 2018 jumlah pengguna aktif smartphone di Indonesia lebih dari 100 juta orang dan ditetapkan sebagai populasi pengguna smartphone terbesar keempat di dunia. Dengan banyaknya pengguna aktif smartphone di Indonesia memungkinkan akses mencari informasi melalui smartphone banyak dilakukan oleh masyarakat dan tidak terkecuali akses mencari informasi seputar Program Studi Sistem Informasi [2].

Saat ini perkembangan teknologi web semakin pesat, sehingga pengimplementasian teknologi baru perlu diterapkan agar dapat meningkatkan performa website. Dengan melihat peluang dari banyaknya pengguna aktif smartphone di Indonesia, maka diperlukan pengoptimalan website Program Studi Sistem Informasi agar mendukung penggunaan melalui smartphone secara optimal serta meningkatkan performa website saat diakses. Adapun untuk mengoptimalkan dan meningkatkan performa website Program Studi Sistem Informasi dengan menerapkan framework AMP (Accelerated Mobile Pages) pada website Program Studi Sistem Informasi.

AMP merupakan proyek inisiatif sumber terbuka dari Google yang menghadirkan solusi untuk situs web seluler yang lebih cepat. AMP bergantung pada AMP HTML yang dibangun sepenuhnya pada teknologi yang ada dan membantu penerbit untuk menulis halaman web yang ringan. Tujuan utama dari teknologi ini adalah untuk menyediakan konten kepada pengguna lebih cepat dalam pemuatan halaman web. Adapun untuk meningkatkan kecepatan halaman AMP yaitu salah satunya caching, yang berfungsi untuk mengoptimalkan waktu pengiriman konten ke pengguna dengan memanfaatkan teknologi Google yang menyediakan Google AMP Cache. Google AMP Cache akan meng-cache semua halaman AMP dan menyajikan ke pengguna tanpa sumber daya yang besar. Google AMP Cache akan menyimpan semua halaman AMP dan membuat konten tersedia untuk dicache oleh pihak ketiga dengan mengikuti batasan AMP [3].

Maka dari itu, dilakukan penelitian yang berjudul "Implementasi Framework Accelerated Mobile Pages Pada Pengembangan Website Program Studi
Sistem Informasi" untuk membandingkan dan menguji performa website Program Studi Sistem Informasi yang menggunakan AMP dan yang tidak menggunakan AMP. Adapun, dari penelitian ini diharapkan mendapatkan hasil pengujian dan perbandingan kedua website serta menilai apakah penerapan framework AMP Accelerated Mobile Pages pada website Program Studi Sistem Informasi layak atau tidak. Selain itu, penelitian ini juga diharapkan dapat digunakan sebagai acuan pengimplementasian framework Accelerated Mobile Pages pada website dan berguna untuk pengembangan penelitian berikutnya.

\section{LANDASANTEORI}

\subsection{AMP (Accelerated Mobile Pages)}

Sistem informasi manajemen merupakan suatu sistem berbasis komputer yang menghasilkan informasi bagi para penggunanya yang memiliki kebutuhan informasi yang didapatkan dari hasil sistem informasi manajemen yang menjelaskan tentang perusahaan yang telah terjadi dimasa lalu, yang sedang terjadi, dan apa yang kemungkinan akan terjadi di masa depan [2].

AMP (Accelerated Mobile Pages) adalah adalah proyek Google dan Twitter. Sejak pencarian seluler menjadi semakin populer, Google merilis pada tahun 2016 sebuah penelitian "cross device" yang memberikan lebih banyak bukti bahwa sejumlah besar konsumen menelusuri web dan melakukan pencarian pada banyak perangkat sepanjang hari. Ini juga menegaskan, bahwa perangkat seluler adalah platform dominan yang digunakan dan itu berarti persentase dari pengguna yang menggunakan perangkat seluler. Hampir $30 \%$ orang hanya mencari di web menggunakan smartphone rata-rata dalam sehari, karena mereka mencari untuk memenuhi kebutuhan mendesak. Google mengklaim bahwa sebagian besar pengguna akan meninggalkan situs jika tidak dimuat dalam tiga detik. Google berfokus pada beberapa faktor yang memengaruhi kecepatan keseluruhan web, seperti CSS, skrip $H T M L$, dan juga gambar.

AMP adalah proyek sumber terbuka yang dirancang untuk membantu penerbit membuat konten yang dioptimalkan untuk seluler yang dimuat secara instan di semua perangkat. AMP memberikan halaman web yang dipangkas hanya menggunakan $H T M L$ 
dan CSS, sehingga webmaster dapat memengaruhi konten dan formulir. JavaScript hanya digunakan di bagianbagian utama AMP, penyedia konten dapat dimasukkan ke halaman [4].

\subsection{Pengujian White Box dan Black Box}

Pengujian software terbagi menjadi 2, yaitu pengujian white box dan pengujian black box. White Box Testing adalah salah satu cara untuk menguji suatu aplikasi atau software dengan cara melihat modul untuk dapat meneliti dan menganalisa kode dari program yang di buat ada yang salah atau tidak. Kalau modul yang telah dan sudah di hasilkan berupa output yang tidak sesuai dengan yang di harapkan maka akan dikompilasi ulang dan di cek kembali kodekode tersebut hingga sesuai dengan yang diharapkan [5]. Sedangkan Black-Box Testing merupakan pengujian yang berfokus pada spesifikasi fungsional dari perangkat lunak, tester dapat mendefinisikan kumpulan kondisi input dan melakukan pengetesan pada spesifikasi fungsional program [6].

\subsection{PageSpeed Insights}

PageSpeed Insights (PSI) adalah tools yang berguna melaporkan kinerja halaman pada perangkat seluler dan desktop, dan memberikan saran tentang bagaimana halaman tersebut dapat ditingkatkan. PSI menyediakan data lab dan lapangan tentang halaman. Data lab berguna untuk debugging masalah kinerja, karena dikumpulkan dalam lingkungan yang terkendali. Namun, data itu mungkin tidak sama persis dengan data nyata. Data lapangan berguna untuk menggambarkan pengalaman pengguna yang sebenarnya, tetapi memiliki serangkaian metrik yang lebih terbatas [7].

\subsection{GTMetrix}

GTMetrix adalah tools pengujian perangkat lunak otomatis untuk mengukur kinerja situs web. GTMetrix dibangun dan dikembangkan oleh Gossamer Threads. Tools ini menggunakan Google Page Speed dan Yahoo YSlow sebagai mesin analisa. Tools ini dimaksudkan untuk mengetahui kinerja suatu website berdasarkan parameter seperti page speed grade, kelas YSlow, waktu buka halaman, ukuran halaman, dan jumlah permintaan HTTP. Hasil tes akan ditampilkan dengan rekomendasi yang harus dilakukan. Berdasarkan informasi terinci di situs GTMetrix, hasil penilaian diberikan dalam bentuk grade dengan skor berupa angka. Nilai tersebut ditandai secara kualitatif dengan huruf A, B, C, D, E, dan F, sedangkan skornya ditandai secara kuantitatif dengan angka [8].

\subsection{Skala Likert}

Skala likert adalah skala yang dapat dipergunakan untuk mengukur sikap, pendapat, dan persepsi seseorang atau sekelompok orang tentang suatu gejala. Ada dua bentuk pertanyaan positif untuk mengukur sikap positif, dan bentuk pertanyaan negatif untuk mengukur sikap negatif. Pertanyaan positif diberi skor $5,4,3,2$, dan 1 . Sedangkan pertanyaan negatif diberi skor 1,2,3,4 dan 5. Bentuk jawaban skala likert adalah sangat setuju, setuju, raguragu, tidak setuju, dan sangat tidak setuju [9].

\section{METODE PENELITIAN}

\subsection{Framework Hevner}

Dalam penelitian ini, usulan metodologi penelitian menggunakan metodologi IS Research Framework [10], dalam menggambarkan secara keseluruhan proses implementasi framework Accelerated Mobile Pages pada pengembangan website Program Studi Sistem Informasi.

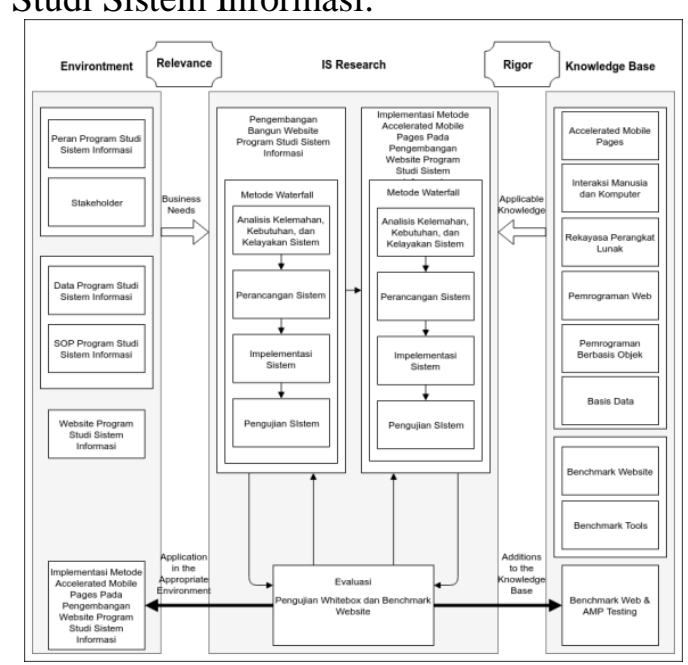

Gambar 1 Framework IS Research

Metodologi IS Research Framework yang meliputi tahap penetapan perspektif pada aspek lingkungan (Environment), tahap proses penelitian (Is Research), serta tahap basis pengetahuan (Knowledge Base). Adapun langkah proses penelitian yang meliputi aspek pendekatan lingkungan seperti peran Prodi Sistem Informasi sebagai tempat penelitian, stakeholder yang terkait, data dan SOP Prodi Sistem Informasi sebagai 
data penelitian yang digunakan, serta website Prodi Sistem Informasi sebagai objek penelitian. Pada aspek proses penelitian mengembangkan website Program Studi Sistem Informasi, pada aspek pengetahuan melakukan pengujian dan perbandingan performa website dengan benchmark tools serta melakukan pengujian validitas AMP (Accelerated Mobile Pages). Dalam proses penelitian menggunakan metode waterfall dengan langkah-langkah dalam pengimplementasian AMP sebagai berikut:

a. Analisis

Pada website Prodi Sistem Informasi dilakukan proses analisis dimulai dari analisis kelemahan, analisis kebutuhan, serta analisis kelayakan sistem.

b. Perancangan

Pada tahap ini dilakukan perancangan sistem yang meliputi perancangan antarmuka seperti mockup sistem, perancangan basis data seperti ERD (Entity Relationship Diagram) dan Class Diagram, serta perancangan alur sistem menggunakan UML (Unified Modeling Language) seperti Use Case Diagram, Sequence Diagram, dan lainnya.

c. Implementasi

Pada tahap ini dilakukan pengembangan sistem pada bagian frontend sistem dengan mengimplementasikan AMP (Accelerated Mobile Pages).

d. Pengujian

Pada tahap ini dilakukan pengujian performa sistem menggunakan tools benchmark dan melakukan pengujian validitas AMP pada sistem.

\subsection{Flowchart Implementasi AMP}

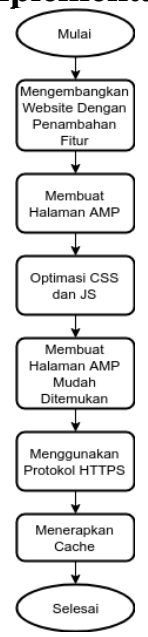

Gambar 2 Flowchart Implementasi AMP

a. Mengembangkan website dengan penambahan fitur
Melakukan pengembangan website dengan penambahan fitur kelola data, kelola konten artikel, kelola pengaturan sistem, dan mengimplementasikan AMP pada frontend website.

b. Membuat halaman AMP

Mengubah setiap komponen website menjadi halaman AMP berdasarkan spesifikasi AMP HTML.

c. Optimasi CSS dan JS

Melakukan optimasi CSS secara inline dan mengganti semua fungsi Javascript pihak ketiga dengan $A M P J S$.

d. Membuat halaman AMP mudah ditemukan

Membuat halaman AMP mudah ditemukan dan mudah dikenali mesin pencari Google menggunakan metadata pihak ketiga seperti Schema.org dan lainnya.

\section{e. Menggunakan protokol HTTPS}

Menggunakan protokol HTTPS agar dapat memanfaatkan semua fitur dari AMP.

\section{f. Menerapkan cache}

Menerapkan sistem cache untuk meningkatkan performa website saat diakses melalui smartphone. Adapun penerapan AMP Cache menggunakan layanan Cloudflare dengan menggunakan fitur Cloudflare AMP cache dan Cloudflare AMP Real URL.

\section{PERANCANGAN SISTEM}

Perancangan sistem dilakukan dengan tujuan untuk memberi gambaran secara umum dari sistem yang akan dikembangkan atau dibangun. Adapun perancangan sistem meliputi perancangan arsitektur sistem, Use Case Diagram, Sequence Diagram, Activity Diagram, Class Diagram, Entity Relationship Diagram, dan perancangan antarmuka sistem.

\subsection{Rancangan Use Case Diagram}

Perancangan Use Case Diagram terbagi menjadi dua yaitu, Frontend dan Backend dapat dilihat pada Gambar 3 dan Gambar 4 berikut: 


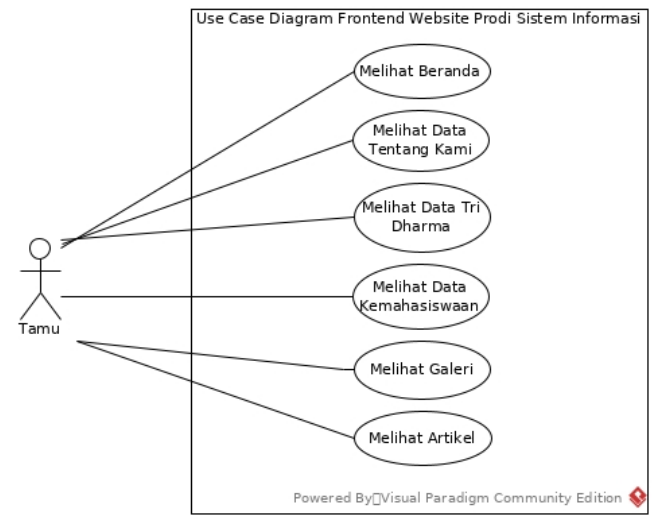

Gambar 3 Use Case Diagram Frontend Use Case Diagram Frontend menjelaskan interaksi pengguna umum (Tamu) dan objek yang dapat diakses. Adapun Use Case Diagram Frontend Website Prodi Sistem Informasi ini terdiri dari Use Case melihat beranda, melihat data tentang kami, melihat data tri dharma, melihat data kemahasiswaan, melihat data galeri, dan melihat data artikel. Untuk melihat spesifikasi use case secara lebih jelas dapat dilihat pada lampiran Spesifikasi Kebutuhan Perangkat Lunak (SKPL).

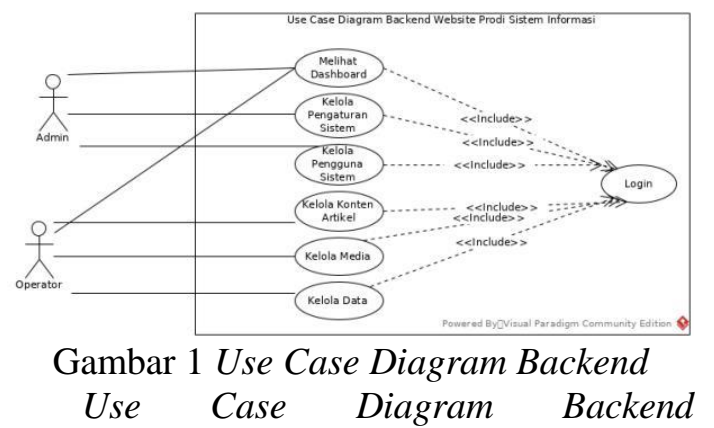
mengambarkan interaksi antara aktor dan fungsi-fungsi di dalam sistem. Pada Use Case Diagram ini menjelaskan interaksi antara admin dan operator dengan objek yang dapat diakses. Adapun Use Case Diagram Backend Website Prodi Sistem Informasi ini terdiri dari Use Case melihat dashboard, kelola pengaturan sistem, kelola pengguna sistem, kelola konten artikel, kelola media, kelola data, dan login.

\subsection{Rancangan Activity Diagram}

Pada Gambar 5 activity diagram umum frontend menjelaskan mengenai alur aktivitas yang terjadi antara aktor tamu dan sistem. Pada activity diagram ini aktor tamu mengakses website Prodi Sistem Informasi dan aktor tamu hanya dapat mengakses frontend website Prodi Sistem Informasi untuk mencari dan melihat informasi seputar Prodi Sistem Informasi. Adapun frontend website Prodi Sistem Informasi di penelitian ini mengimplementasikan framework Accelerated Mobile Pages yang bertujuan untuk mengoptimalkan performa website saat diakses menggunakan smartphone dan memudahkan dalam pencarian website melalui mesin pencari Google sehingga informasi seputar Program Studi Sistem Informasi dapat dengan mudah diakses pengguna.

Pada Gambar 6 activity diagram umum backend menjelaskan mengenai alur aktivitas yang terjadi antara aktor dan sistem. Pada activity diagram ini aktor dibagi menjadi dua jenis yaitu operator, dan admin. Pada aktor admin dan operator aktivitas dimulai saat aktor berhasil melakukan login dan kemudian setelah login akan dialihkan ke halaman dashboard sistem berdasarkan tipe hak akses pengguna. Aktor admin berfungsi sebagai pemegang kontrol sistem terhadap kelola data pengguna dan pengaturan sistem. Sedangkan aktor operator sebagai pengelola data sistem seperti kelola data konten artikel, kelola media, kelola data Prodi Sistem Informasi secara keseluruhan.

\subsection{Rancangan Sequencial Diagram}

Sequence Diagram menggambarkan interaksi antara objek, display, dan pengguna di dalam sistem sesuai dengan urutan, rangkaian waktu, dan interaksi pertukaran pesan antar objek. Berikut ini merupakan beberapa contoh sequence diagram yang terdapat pada sistem WPSI (Implementasi Framework Accelerated Mobile Pages Pada Pengembangan Website Program Studi Sistem Informasi). Adapun untuk sequence diagram secara lengkap dapat dilihat pada lampiran DPPL (Deskripsi Perancangan Perangkat Lunak).

Deskripsi sequence diagram melihat beranda adalah sebagai berikut :

a. Sequence ini dimulai ketika aktor mengakses halaman indeks beranda, sistem menjalankan route get('/').

b. Contoller beranda menjalankan fungsi beranda() dan menjalankan query untuk menampilkan data karosel, dosen, sarana dan prasarana, kerjasama, prestasi, dan artikel statis untuk ditampilkan pada halaman beranda.

c. Sistem menampilkan halaman beranda beserta data umum di halaman beranda.

d. Aktor dapat melihat halaman beranda. 
Coding: Jurnal Komputer dan Aplikasi

Volume 08, No. 02 (2020), hal 67-78

ISSN: $2338-493 \mathrm{X}$

Adapun perancangan sequence diagram melihat beranda dapat dilihat pada Gambar 7 berikut.

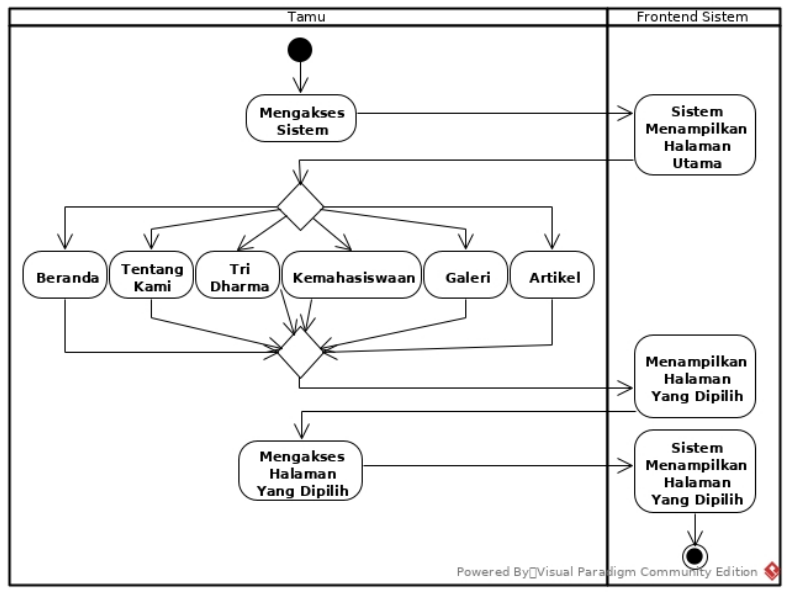

Gambar 5 Activity Diagram Umum Frontend

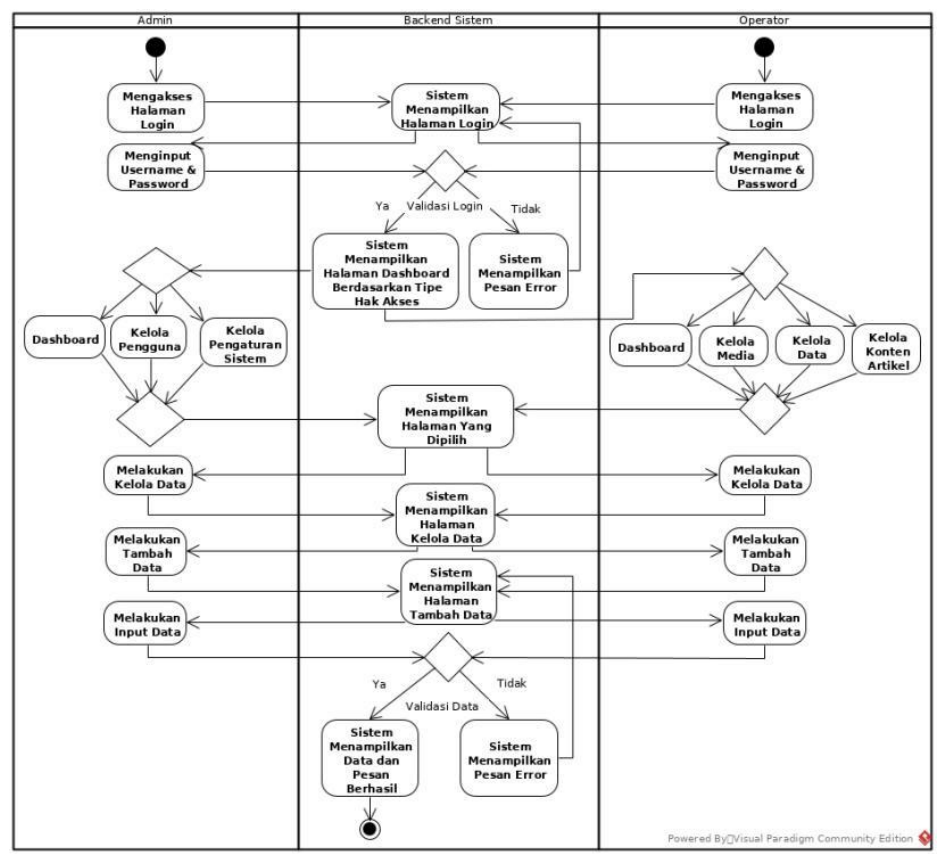

Gambar 6 Activity Diagram Umum Backend

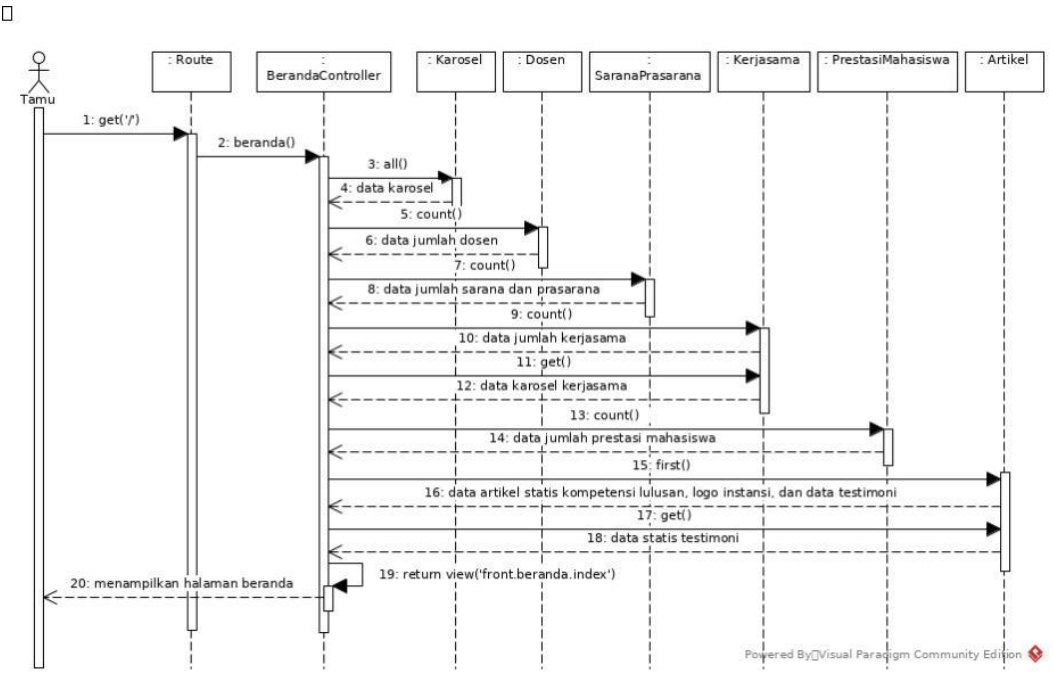


Gambar 7 Sequence Diagram: Melihat Beranda

\subsection{Rancangan Entity Relationship Diagram}

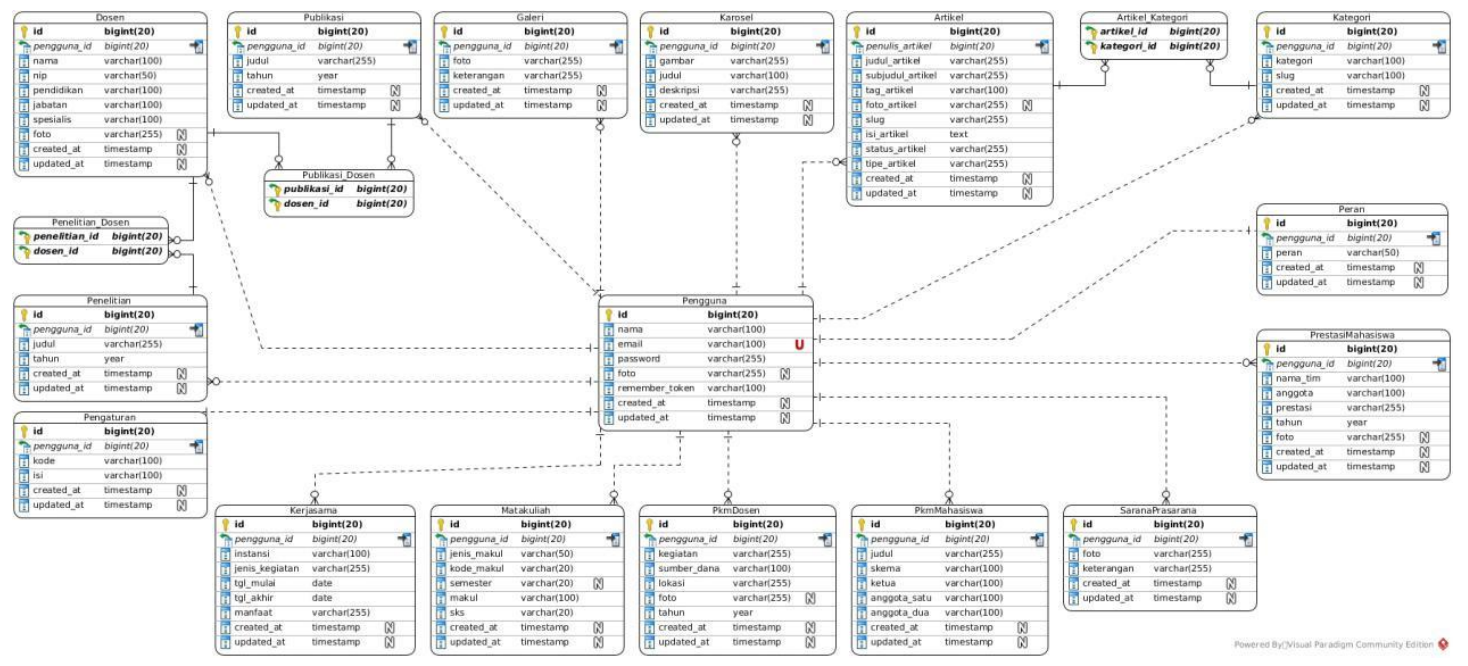

Gambar 8 Entity Relationship Diagram

Pada Gambar 8 merupakan gambaran akan rancangan basis data sistem yang akan dibangun. Pada perancangan Entity Relationship Diagram terdapat 16 entitas yang terdiri dari artikel, dosen, galeri, karosel, kategori, kerjasama, matakuliah, penelitian, pengaturan, pengguna, peran, pkm dosen, pkm mahasiswa, prestasi mahasiswa, publikasi, dan sarana prasarana. Setiap entitas memiliki atribut batasan masing-masing yangdapat dilihat pada lampiran SKPL (Spesifikasi Kebutuhan Perangkat Lunak).

\section{HASIL DAN PEMBAHASA}

\subsection{Hasil}

Setelah melakukan analisis dan perancangan sistem maka akan dilakukan implementasi sistem. Berikut hasil dari sistem yang telah diimplementasikan ke dalam coding dapat dilihat pada gambar 9 dan 10

Berikut ini merupakan hasil implementasi rancangan antarmuka sistem.

a. Halaman beranda

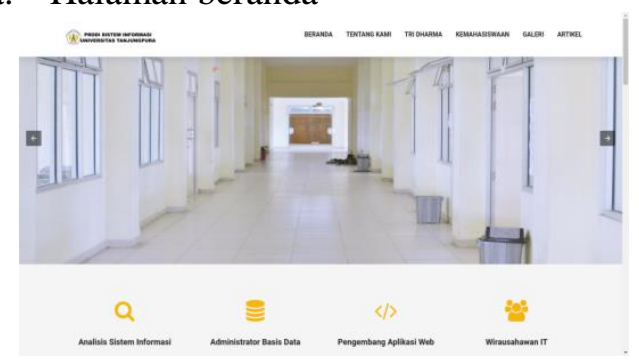

Gambar 9 Implementasi antarmuka halaman beranda versi desktop

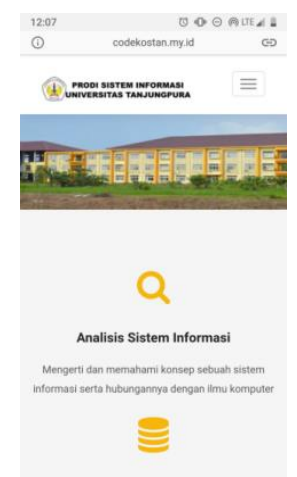

Gambar 10 Implementasi antarmuka halaman beranda versi Mobile

Pada Gambar 9 merupakan implementasi rancangan antarmuka halaman beranda pada versi desktop dan Gambar 10 merupakan implementasi rancangan antarmuka halaman beranda versi mobile dengan menggunakan AMP. Pada halaman ini terdapat ringkasan informasi seputar Program Studi Sistem Informasi yang dapat dilihat oleh pengguna tamu.

b. Halaman galeri

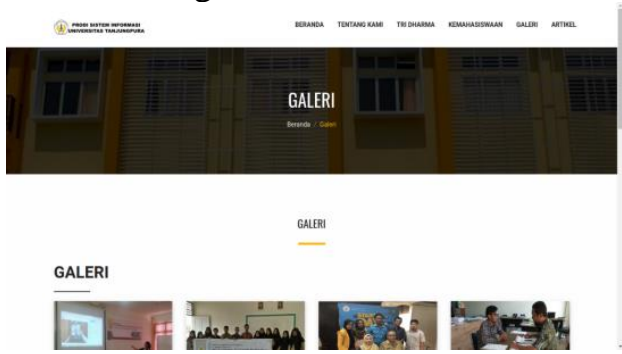

Gambar 11 Implementasi antarmuka halaman galeri versi desktop 


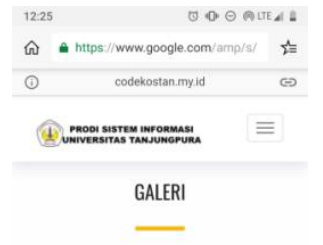

GALERI

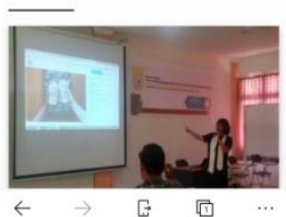

Gambar 12 Implementasi antarmuka halaman galeri versi mobile

Pada Gambar 11 merupakan implementasi rancangan antarmuka halaman galeri pada versi desktop dan Gambar 12 merupakan implementasi rancangan antarmuka halaman beranda pada versi mobile dengan menggunakan AMP. Pada halaman ini terdapat foto galeri seputar Prodi Sistem Informasi yang dapat dilihat oleh pengguna tamu.

\subsection{Pembahasan}

Pembahasan dilakukan dengan implementasi Accelerated Mobile Pages, pengujian fungsional sistem, pengujian $A M P$ tools dan benchmark tools, dan pengujian antarmuka sistem.

\subsubsection{Implementasi Accelerated Mobile Pages \\ Tahapan implementasi AMP} (Accelerated Mobile Pages) yaitu sebagai berikut:

a. Membuat halaman AMP berdasarkan spesifikasi HTML AMP

Pada tahap ini mengubah format HTML 5 menjadi halaman AMP berdasarkan spesifikasi HTML AMP. Selain itu, dilakukan perubahan setiap komponen HTML 5 dengan komponen HTML AMP.

b. Mengubah CSS external menjadi inline CSS

Pada tahap ini mengubah CSS yang digunakan secara external menjadi CSS secara inline dan mengoptimasi CSS dengan menggunakan tools uncss-online.com untuk membersihkan CSS yang tidak digunakan seperti selektor class dan id pada CSS.

c. Mengganti Javascript dengan AMP JS

Pada tahap ini mengganti semua Javascript dari pihak ketiga dan menggantinya dengan AMP JS.

d. Membuat halaman AMP mudah ditemukan
Pada tahap ini membuat halaman AMP agar mudah ditemukan oleh mesin pencari Google dengan menautkan halaman dengan tag link dan mengintegrasikan metadata tambahan dari pihak ketiga seperti Schema.org dan lainnya.

e. Menggunakan protokol HTTPS

Pada tahap ini menggunakan protokol HTTPS sebagai syarat halaman AMP agar dapat memanfaatkan sepenuhnya semua fitur dari AMP.

f. Menggunakan Cache pada halaman AMP

Pada tahap ini menggunakan AMP cache guna meningkatkan kinerja website saat diakses melalui smartphone. Adapun pada penelitian ini menggunakan layanan Cloudflare dengan menggunakan fitur Cloudflare AMP cache dan Cloudflare AMP Real URL.

Setelah implementasi AMP sudah dilakukan, selanjutnya perlunya melakukan hosting website. Adapun pada penelitian WPSI (Implementasi Framework Accelerated Mobile Pages Pada Pengembangan Website Program Studi Sistem Informasi) di hosting pada domain codekostan.my.id untuk yang menggunakan cloud server Google Cloud dan yang menggunakan server shared hosting pada domain pecandukopi.my.id. Kemudian agar implementasi AMP dapat optimal berjalan dan terindeks mesin pencari Google maka perlu adanya SEO (Search Engine Optimization). Adapun pada penelitian ini langkah-langkahnya sebagai berikut:

a. Mendaftarkan website ke Google Webmasters

Pada tahap ini mendaftarkan alamat url website ke Google Webmasters agar website dapat dikenali oleh mesin pencari google saat pengguna mencarinya.

b. Membuat sitemap

Pada tahap ini membuat skrip sitemap yang berfungsi agar mempermudah pengguna menemukan website, website cepat terindeks, dan website berinteraksi lebih baik dengan mesin pencari.

c. Mengimplementasikan cache

Pada tahap ini mengimplementasikan cache pada web AMP dengan menggunakan layanan Cloudflare yaitu Cloudflare AMP Real URL. Dengan adanya cache dapat mempercepat kinerja website saat diakses dan memudahkan mesin pencari Google dalam meng-cache AMP. 
Coding: Jurnal Komputer dan Aplikasi

Volume 08, No. 02 (2020), hal 67-78

ISSN: $2338-493 \mathrm{X}$

Berikut ini merupakan spesifikasi AMP HTML dan contoh perbandingan kode program yang menggunakan AMP HTML dan Tanpa AMP:

a. Spesifikasi AMP HTML

Tabel 1 Spesifikasi AMP HTML

\begin{tabular}{|c|c|c|}
\hline & & 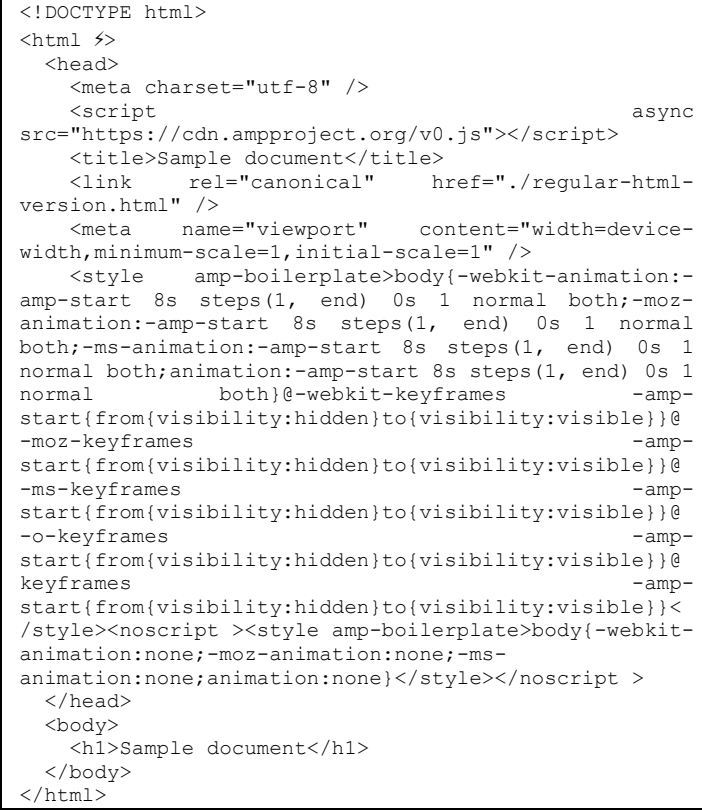 \\
\hline
\end{tabular}

b. Perbandingan kode AMP dan tanpa AMP

Tabel 2 Perbandingan AMP Carousel dan tanpa AMP

\begin{tabular}{|c|}
\hline AMP \\
\hline 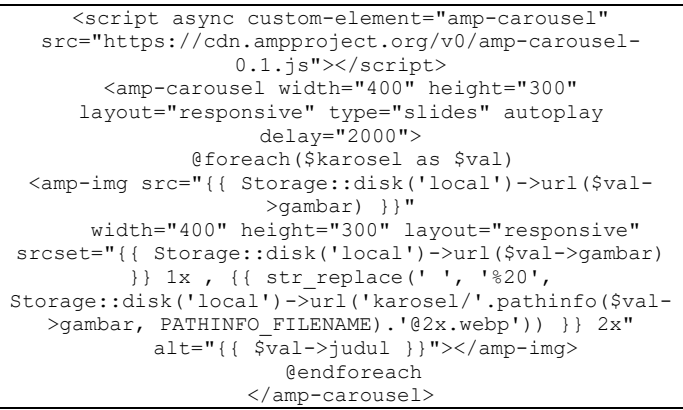 \\
\hline Tanpa AMP \\
\hline 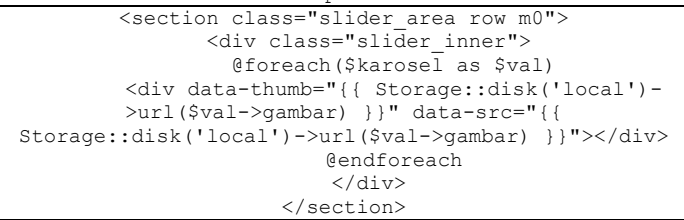 \\
\hline
\end{tabular}

\subsubsection{Pengujian Fungsional Sistem}

Pengujian fungsional sistem dilakukan oleh admin Program Studi Sistem Informasi FMPA UNTAN untuk mengetahui apakah fungsi di dalam sistem dapat berjalan sesuai dengan yang diharapkan atau tidak. Pada Tabel 3 merupakan beberapa contoh hasil pengujian fungsional sistem, untuk secara lengkapnya dapat dilihat pada lampiran PDHUPL (Perencanaan, Deskripsi, dan Hasil
Uji Perangkat Lunak).

Tabel 3 Pengujian fungsional sistem

\begin{tabular}{|c|c|c|c|c|}
\hline $\begin{array}{c}\text { No } \\
\text {. }\end{array}$ & Kelas Uji & Pengujian & $\begin{array}{c}\text { Keluaran } \\
\text { Yang } \\
\text { Diharapka } \\
\text { n }\end{array}$ & $\underset{\mathbf{n}}{\text { Kesimpula }}$ \\
\hline 1. & $\begin{array}{l}\text { Pengujian } \\
\text { halaman } \\
\text { beranda } \\
\text { oleh } \\
\text { pengguna }\end{array}$ & $\begin{array}{l}\text { Pengguna } \\
\text { mengakses } \\
\text { halaman } \\
\text { beranda }\end{array}$ & $\begin{array}{l}\text { Pengguna } \\
\text { dapat } \\
\text { mengakses } \\
\text { halaman } \\
\text { beranda } \\
\text { pada WPSI }\end{array}$ & Berhasil \\
\hline$\ldots$. & …….......... & ................... & ..................... & ................. \\
\hline 16. & $\begin{array}{l}\text { Pengujian } \\
\text { halaman } \\
\text { artikel } \\
\text { oleh } \\
\text { pengguna }\end{array}$ & $\begin{array}{l}\text { Pengguna } \\
\text { memilih } \\
\text { menu } \\
\text { artikel }\end{array}$ & $\begin{array}{l}\text { Pengguna } \\
\text { dapat } \\
\text { mengakses } \\
\text { halaman } \\
\text { artikel pada } \\
\text { WPSI }\end{array}$ & Berhasil \\
\hline
\end{tabular}

\subsubsection{Pengujian AMP Tools dan Benchmark Tools}

Pengujian AMP Tools digunakan untuk menguji validitas kode AMP yang digunakan dan pengujian dengan benchmark tools digunakan untuk menguji performa website dan melakukan perbandingan sistem yang menggunakan AMP dan tanpa AMP. Adapun untuk menguji kode AMP menggunakan Google AMP Test dan AMP Validator. Sedangkan untuk menguji performa website menggunakan PageSpeed Insights dan GTMetrix.

1. Pengujian kode AMP (Accelerated Mobile Pages)

a. Google AMP Test

Pengujian Halaman AMP dengan Google AMP Test mendapatkan hasil valid. Berikut ini contoh beberapa pengujian halaman AMP dengan Google AMP Test, untuk secara lengkapnya dapat dilihat pada lampiran PDHUPL (Perencanaan, Deskripsi, dan Hasil Uji Perangkat Lunak).

Tabel 4 Pengujian halaman AMP dengan Google AMP Test

\begin{tabular}{|c|c|c|}
\hline No. & Pengujian AMP & Tinjauan \\
\hline \multirow{8}{*}{1.} & Halaman beranda & \multirow{2}{*}{$\equiv$ Google 18} \\
\hline & Hasil & \\
\hline & \multirow[t]{6}{*}{ Valid } & $\therefore=$ \\
\hline & & 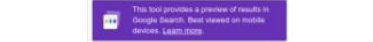 \\
\hline & & $\therefore=0$ \\
\hline & & 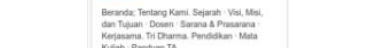 \\
\hline & & nomsic \\
\hline & & 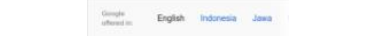 \\
\hline \multirow{3}{*}{...... } & …………… & \multirow{4}{*}{ 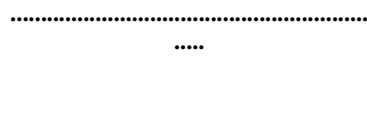 } \\
\hline & Hasil & \\
\hline & & \\
\hline & & \\
\hline
\end{tabular}


Coding: Jurnal Komputer dan Aplikasi

Volume 08, No. 02 (2020), hal 67-78

ISSN: 2338-493X

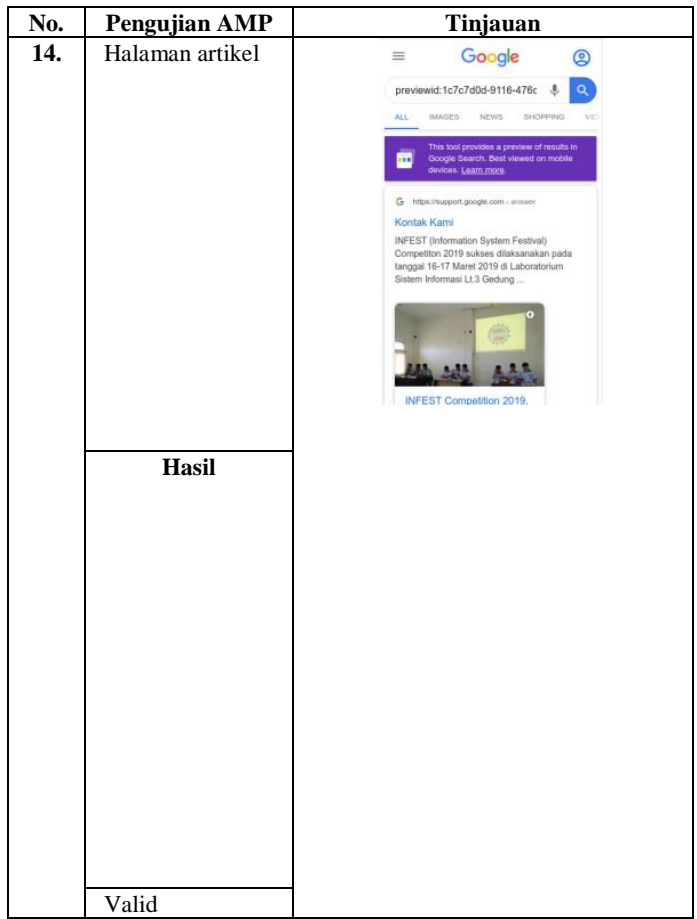

b. AMP Validator

Pengujian Halaman AMP dengan AMP Validator mendapatkan hasil lulus. Berikut ini beberapa contoh pengujian halaman AMP dengan AMP Validator, untuk secara lengkapnya dapat dilihat pada lampiran PDHUPL (Perencanaan, Deskripsi, dan Hasil Uji Perangkat Lunak).

Tabel 5 Pengujian halaman AMP dengan

\begin{tabular}{|c|c|c|}
\hline No. & Pengujian AMP & Hasil \\
\hline 1. & Halaman Beranda & Lulus \\
\hline 2. & Halaman Sejarah & Lulus \\
\hline .. & . & $\ldots$ \\
\hline 14. & Halaman Artikel & Lulus \\
\hline
\end{tabular}

2. Pengujian dan perbandingan performa website

Berikut ini merupakan beberapa contoh pengujian dan perbandingan performa website, untuk secara lengkapnya dapat dilihat pada lampiran PDHUPL (Perencanaan, Deskripsi, dan Hasil Uji Perangkat Lunak). Pada Tabel 6 merupakan spesifikasi dari cloud server Google Cloud dan server shared hosting yang digunakan sistem dan dilakukan pengujian performa sistem.

Tabel 6 Spesifikasi server

\begin{tabular}{|l|c|c|c|}
\hline \multicolumn{1}{|c|}{ Server } & CPU & Memory & Storage \\
\hline Google Cloud & 1 Core & $3,75 \mathrm{~GB}$ & $50 \mathrm{~GB}$ \\
\hline $\begin{array}{l}\text { Shared } \\
\text { Hosting }\end{array}$ & 1 Core & $1 \mathrm{~GB}$ & $3 \mathrm{~GB}$ \\
\hline
\end{tabular}

Tabel 7 Pengujian dan perbandingan performa sistem WPSI menggunakan cloud server Google Cloud dengan PageSpeed Insights

\begin{tabular}{|c|c|c|c|c|c|c|c|c|c|}
\hline \multirow{4}{*}{ No. } & \multirow{4}{*}{ Pengujian } & \multicolumn{8}{|c|}{ Kriteria Penilaian } \\
\hline & & \multicolumn{4}{|c|}{ AMP } & \multicolumn{4}{|c|}{ Non AMP } \\
\hline & & \multicolumn{2}{|c|}{ Mobile } & \multicolumn{2}{|c|}{ Desktop } & \multicolumn{2}{|c|}{ Mobile } & \multicolumn{2}{|c|}{ Desktop } \\
\hline & & $\begin{array}{l}\text { Page } \\
\text { Speed }\end{array}$ & $\begin{array}{c}\text { Response } \\
\text { Time }\end{array}$ & $\begin{array}{l}\text { Page } \\
\text { Speed }\end{array}$ & $\begin{array}{l}\text { Response } \\
\text { Time }\end{array}$ & $\begin{array}{l}\text { Page } \\
\text { Speed }\end{array}$ & $\begin{array}{c}\text { Response } \\
\text { Time }\end{array}$ & $\begin{array}{l}\text { Page } \\
\text { Speed }\end{array}$ & $\begin{array}{c}\text { Response } \\
\text { Time }\end{array}$ \\
\hline 1. & Halaman Beranda & 94 & $\begin{array}{c}190 \\
\text { milidetik }\end{array}$ & 100 & $\begin{array}{c}180 \\
\text { milidetik }\end{array}$ & 76 & $\begin{array}{c}210 \\
\text { milidetik }\end{array}$ & 98 & $\begin{array}{c}230 \\
\text { milidetik }\end{array}$ \\
\hline 2. & Halaman Sejarah & 96 & $\begin{array}{c}180 \\
\text { milidetik }\end{array}$ & 99 & $\begin{array}{c}180 \\
\text { milidetik }\end{array}$ & 80 & $\begin{array}{c}230 \\
\text { milidetik }\end{array}$ & 99 & $\begin{array}{c}260 \\
\text { milidetik }\end{array}$ \\
\hline 3. & $\begin{array}{l}\text { Halaman Visi, } \\
\text { Misi, dan Tujuan }\end{array}$ & 96 & $\begin{array}{c}180 \\
\text { milidetik }\end{array}$ & 100 & $\begin{array}{c}180 \\
\text { milidetik }\end{array}$ & 83 & $\begin{array}{c}270 \\
\text { milidetik }\end{array}$ & 99 & $\begin{array}{c}240 \\
\text { milidetik }\end{array}$ \\
\hline$\ldots$ & 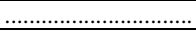 & ………….... & ………….... & …………... & ………….... & …………... & ………....... & …………..... & ………….... \\
\hline 14 & Halaman Artikel & 96 & $\begin{array}{c}200 \\
\text { milidetik }\end{array}$ & 97 & $\begin{array}{c}180 \\
\text { milidetik }\end{array}$ & 82 & $\begin{array}{c}240 \\
\text { milidetik }\end{array}$ & 100 & $\begin{array}{c}220 \\
\text { milidetik }\end{array}$ \\
\hline & Total Skor & \multicolumn{2}{|c|}{1187} & \multicolumn{2}{|c|}{$\frac{1}{1375}$} & \multicolumn{2}{|c|}{$\frac{1}{1137}$} & \multicolumn{2}{|c|}{1389} \\
\hline
\end{tabular}

Tabel 8 Pengujian dan perbandingan performa sistem WPSI menggunakan server shared hosting dengan PageSpeed Insights

\begin{tabular}{|c|c|c|c|c|c|c|c|c|c|}
\hline \multirow{4}{*}{ No. } & \multirow{4}{*}{ Pengujian } & \multicolumn{8}{|c|}{ Kriteria Penilaian } \\
\hline & & \multicolumn{4}{|c|}{ AMP } & \multicolumn{4}{|c|}{ Non AMP } \\
\hline & & \multicolumn{2}{|c|}{ Mobile } & \multicolumn{2}{|c|}{ Desktop } & \multicolumn{2}{|c|}{ Mobile } & \multicolumn{2}{|c|}{ Desktop } \\
\hline & & $\begin{array}{c}\text { Page } \\
\text { Speed }\end{array}$ & $\begin{array}{c}\text { Response } \\
\text { Time }\end{array}$ & $\begin{array}{l}\text { Page } \\
\text { Speed }\end{array}$ & $\begin{array}{c}\text { Response } \\
\text { Time }\end{array}$ & $\begin{array}{l}\text { Page } \\
\text { Speed }\end{array}$ & $\begin{array}{l}\text { Response } \\
\text { Time }\end{array}$ & $\begin{array}{c}\text { Page } \\
\text { Speed }\end{array}$ & $\begin{array}{c}\text { Response } \\
\text { Time }\end{array}$ \\
\hline 1. & Halaman Beranda & 90 & $\begin{array}{c}470 \\
\text { milidetik }\end{array}$ & 98 & $\begin{array}{c}350 \\
\text { milidetik }\end{array}$ & 76 & $\begin{array}{c}510 \\
\text { milidetik }\end{array}$ & 98 & $\begin{array}{c}520 \\
\text { milidetik }\end{array}$ \\
\hline 2. & Halaman Sejarah & 95 & $\begin{array}{c}360 \\
\text { milidetik }\end{array}$ & 97 & $\begin{array}{c}350 \\
\text { milidetik }\end{array}$ & 80 & $\begin{array}{c}560 \\
\text { milidetik }\end{array}$ & 99 & $\begin{array}{c}550 \\
\text { milidetik }\end{array}$ \\
\hline 3. & $\begin{array}{c}\text { Halaman Visi, } \\
\text { Misi, dan Tujuan }\end{array}$ & 92 & $\begin{array}{c}420 \\
\text { milidetik }\end{array}$ & 97 & $\begin{array}{c}440 \\
\text { milidetik }\end{array}$ & 82 & $\begin{array}{c}480 \\
\text { milidetik }\end{array}$ & 99 & $\begin{array}{c}510 \\
\text { milidetik }\end{array}$ \\
\hline$\ldots$ & 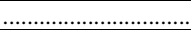 & …………...... & ………….... & ………….... & …………....... & …………...... & …………...... & …………......... & …………..... \\
\hline 14 & Halaman Artikel & 69 & $\begin{array}{c}380 \\
\text { milideik }\end{array}$ & 97 & $\begin{array}{c}490 \\
\text { milidetik }\end{array}$ & 80 & $\begin{array}{c}420 \\
\text { milidetik }\end{array}$ & 98 & $\begin{array}{c}430 \\
\text { milidetik }\end{array}$ \\
\hline & Total Skor & \multicolumn{2}{|c|}{1090} & \multicolumn{2}{|c|}{1364} & \multicolumn{2}{|c|}{$\frac{1}{1140}$} & \multicolumn{2}{|c|}{1381} \\
\hline
\end{tabular}


Coding: Jurnal Komputer dan Aplikasi

Volume 08, No. 02 (2020), hal 67-78

ISSN: $2338-493 \mathrm{X}$

Tabel 9 Pengujian dan perbandingan performa sistem WPSI menggunakan cloud server Google Cloud dengan GTMetrix

\begin{tabular}{|c|c|c|c|c|c|}
\hline \multirow{3}{*}{ No. } & \multirow{3}{*}{ Pengujian } & \multicolumn{4}{|c|}{ Kriteria Penilaian } \\
\hline & & \multicolumn{2}{|c|}{$\overline{\text { AMP }}$} & \multicolumn{2}{|c|}{ Tanpa AMP } \\
\hline & & PageSpeed Score & YSlow Score & PageSpeed Score & YSlow Score \\
\hline 1. & Halaman Beranda & $\mathrm{A}(96 \%)$ & $\mathrm{A}(90 \%)$ & B $(88 \%)$ & $\mathrm{C}(77 \%)$ \\
\hline 2. & Halaman Sejarah & B $(88 \%)$ & A $(90 \%)$ & B $(85 \%)$ & B (85\%) \\
\hline 3. & Halaman Visi, Misi, dan Tujuan & A $(96 \%)$ & A $(90 \%)$ & A $(94 \%)$ & B (85\%) \\
\hline …........ & 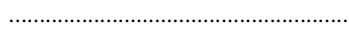 & 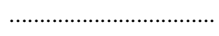 & ……........... & 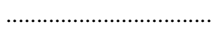 & 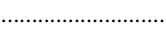 \\
\hline 14. & Halaman Artikel & A $(94 \%)$ & A $(90 \%)$ & A $(92 \%)$ & B (85\%) \\
\hline & Total Skor & $1292 \%$ & $1257 \%$ & $1263 \%$ & $1174 \%$ \\
\hline
\end{tabular}

Tabel 10 Pengujian dan perbandingan performa sistem WPSI menggunakan server shared hosting dengan GTMetrix

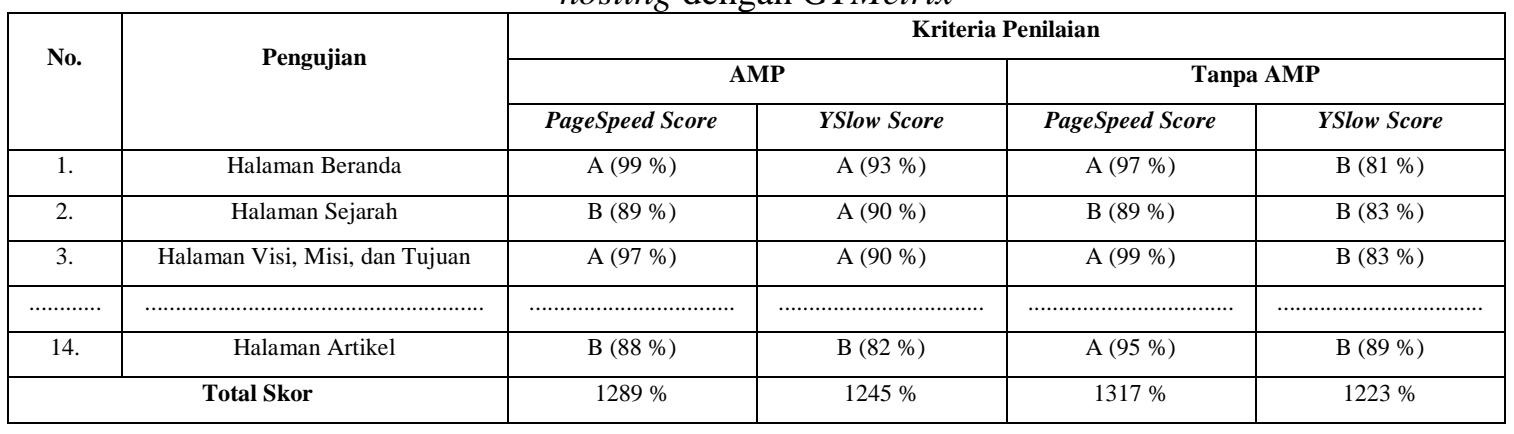

\subsection{Pengujian Antarmuka Sistem}

Berdasarkan hasil pengujian antarmuka perangkat lunak yang dilakukan kepada masyarakat umum dan mahasiswa dengan menggunakan kuesioner online dan diisi oleh 46 responden dan dilakukan perhitungan hasil kuesioner dengan menggunakan skala likert diperoleh nilai $88.07 \%$, dan berdasarkan interval yang telah dihitung penilaian responden terhadap perangkat lunak masuk kedalam kategori baik sekali.

Tabel 11 Hasil pengujian antarmuka sistem

\begin{tabular}{|c|c|c|c|c|c|c|}
\hline No. & Butir Uji & Baik Sekali & Baik & Cukup & Kurang & $\begin{array}{c}\text { Kurang } \\
\text { Sekali }\end{array}$ \\
\hline 1. & $\begin{array}{c}\text { Bagaimana pendapat anda mengenai kemudahan } \\
\text { bernavigasi atau kemudahan pengoperasian saat } \\
\text { mengakses website melalui smartphone? }\end{array}$ & 28 & 17 & 1 & 0 & 0 \\
\hline 2. & $\begin{array}{l}\text { Bagaimana pendapat anda mengenai bentuk font } \\
\text { pada aplikasi (kemudahan dalam pembacaan)? }\end{array}$ & 19 & 25 & 2 & 0 & 0 \\
\hline 3. & $\begin{array}{c}\text { Bagaimana pendapat anda mengenai responsif pada } \\
\text { setiap halaman website? }\end{array}$ & 23 & 20 & 3 & 0 & 0 \\
\hline ......... & , & ..................... & … $\ldots \ldots \ldots \ldots \ldots \ldots$ & … $\ldots \ldots \ldots \ldots \ldots \ldots \ldots$ & ….................. & ...................... \\
\hline 7. & $\begin{array}{c}\text { Bagaimana menurut anda mengenai keseluruhan } \\
\text { website? }\end{array}$ & 20 & 19 & 7 & 0 & 0 \\
\hline
\end{tabular}

\section{KESIMPULAN}

Berdasarkan hasil penelitian yang telah dilakukan, maka terdapat beberapa kesimpulan yang dapat diambil yaitu sebagai berikut:

a. Pengembangan website Program Studi Sistem Informasi dengan menambah fitur kelola data, kelola konten artikel, pengaturan sistem, dan menerapkan framework AMP (Accelerated Mobile Pages) telah dilakukan sesuai dengan persyaratan AMP yang harus dipenuhi. Adapun dalam pengimplementasian AMP semua komponen website harus berdasarkan spesifikasi $A M P H T M L$, menggunakan CSS teroptimasi secara inline, mengganti semua fungsi javascript pihak ketiga menggunakan AMP JS, menerapkan caching website menggunakan AMP Cache, dan menggunakan protokol HTTPS serta membuat halaman AMP mudah ditemukan oleh mesin pencari. Selain itu semua persyaratan AMP telah berhasil di implementasikan dan dilakukan pengujian kode AMP dengan hasil AMP valid.

b. Pengujian performa dengan PageSpeed Insights pada sistem yang menggunakan AMP untuk mode mobile dengan cloud 
server Google Cloud diperoleh hasil total skor 1.187 poin dan menggunakan server shared hosting diperoleh hasil total skor 1.090 poin. Dari hasil tersebut dapat diketahui bahwa performa AMP dipengaruhi juga oleh jenis server dengan selisih 97 poin, tetapi performa AMP masih lebih cepat dibanding tanpa AMP.

c. Pengujian performa dengan GTMetrix pada sistem yang menggunakan AMP dengan cloud server Google Cloud diperoleh hasil total skor PageSpeed $1.292 \%$ dan total skor YSlow $1.257 \%$. Sedangkan menggunakan server shared hosting diperoleh hasil total skor PageSpeed $1.289 \%$ dan total skor YSlow $1.245 \%$. Dari hasil tersebut dapat diketahui bahwa performa AMP dipengaruhi juga oleh jenis server dengan selisih skor PageSpeed 3\% dan skor YSlow $12 \%$.

d. Dari hasil pengujian fungsional sistem yang dilakukan kepada pihak Program Studi Sistem Informasi, sistem dapat berjalan sesuai fungsi yang telah dirancang. Sedangkan hasil pengujian antarmuka sistem kepada 46 responden diperoleh persentase 88, $07 \%$ dan masuk kedalam kategori baik sekali.

\section{SARAN}

Adapun saran untuk penelitian selanjutnya sebagai berikut:

a. Diharapkan penelitian selanjutnya dapat mengembangkan dalam pengimplementasian AMP maupun menggunakan metode lain yang lebih baik lagi.

b. Dalam pengujian ini masih terdapat beberapa kekurangan dan diharapkan penelitian selanjutnya dapat menemukan perbaikan terhadap masalah dalam pengimplementasian AMP yaitu, di browser Google Chrome dan Opera status keterangan AMP tidak muncul pada header website dan skor pengujian performa website pada halaman AMP yang terdapat tabel data mendapatkan skor lebih rendah dari pada halaman tanpa AMP.

\section{DAFTAR PUSTAKA}

[1]Program Studi Sistem Informasi. 2017. Buku Pedoman Akademik
Program Studi Sistem Informasi, Pontianak: Program Studi Sistem Informasi FMIPA UNTAN.

[2]Emarketer. 2014. 2 Billion Consumers Worldwide to Get Smart(phones) by 2016: Over half of mobile phone users globally will have smartphones in 2018,

Dalam(https://www.emarketer.com/A rticle/2-Billion-Consumers-

Worldwide-S martphones-by2016/1011694), $10 \quad$ Oktober 2019.

[3]Minárik, Daniel. 2017. “Accelerated MobilePages."https://is.muni.cz/th/bx s 1s/thesis.pdf. Brno: Masaryk University Faculty of Informatics.

[4]Miklosik, Červenka, Hlavatý, 2017. Impact Of Accelerated Mobile Pages Format On Corporate Web Sites. Bratislava: University of Economics in Bratislava.

[5]Nidhra, Srinivas. 2012. "Black Box and White Box Testing Techniques - A Literature Review.” International Journal of Embedded Systems and Applications Vol. 2 No.2, 29-50.

[6]Khan, Mohd Ehmer. 2011. "Different Approaches to White Box Testing Technique for Finding Errors." International Journal of Software Engineering and its Applications Vol. 2 No. 4, 31-40.

[7]Google. PageSpeed Insights, Dalam (https://developers.google.com/speed/ d ocs/insights/v5/about), 10 Oktober 2019.

[8]Fryonanda dan Ahmad. 2017. "Analisis Website Perguruan Tinggi Berdasarkan Keinginan Search Engine Menggunakan Automated Software Testing GTmetrix." Analisis Website Perguruan Tinggi Berdasarkan Vol. $\quad 4$ No. 2, 179-183.

[9]Djaali dan Muljono, P . 2008. Pengukuran dalam Bidan Pendidikan. Jakarta: PT.Grasindo.

[10]Hevner, March, Park, and Ram. 2004. "Design Science in Information Systems Research." MIS Quarterly Vol. 28 No. 1, 75-105. 